\title{
APPROACHES FOR JUSTIFICATION STRATEGY TECHNICAL MODERNIZATION OF AGRICULTURE GIVEN THE CHARACTERISTICS OF AGRICULTURAL DEVELOPMENT AND RESOURCE PROVISION SUBJECTS OF THE FEDERATION
}

\author{
МЕТОДИЧЕСКИЕ ПОДХОДЫ К ОБОСНОВАНИЮ СТРАТЕГИИ ТЕХНИЧЕСКОЙ \\ МОДЕРНИЗАЦИИ СЕЛЬСКОГО ХОЗЯЙСТВА С УЧЕТОМ ОСОБЕННОСТЕЙ РАЗВИТИЯ \\ СЕЛЬСКОГО ХОЗЯЙСТВА И РЕСУРСНОЙ ОБЕСПЕЧЕННОСТИ СУБЪЕКТА \\ ФЕДЕРАЦИИ
}

Polukhin A.A., Candidate of Economic Sciences, Associate Professor Полухин А.А., кандидат экономических наук, доцент

\author{
All-Russian Research Institute of Agricultural Economics, Moscow, Russia \\ Всероссийский научно-исследовательский институт экономики сельского хозяйства, \\ Москва, Россия \\ E-mail: polukhinogac@yandex.ru
}

\begin{abstract}
The article presents the author developed and tested methodical approaches to the justification of the strategic directions of technical modernization of regional agriculture. Given the rationale for the structural analysis of the existing fleet of vehicles on the statistical data and the results of a questionnaire study. For the purpose of grouping features of the technical equipment in the region prompted the use of a SWOT analysis. To increase the availability of small farms to modern techniques and technologies proposed to create a machine-technological station in the form of a consumer cooperative.

АННОТАЦИЯ

В статье представлены разработанные и апробированные автором методические подходы к обоснованию стратегических направлений технической модернизации регионального сельского хозяйства. Дано обоснование необходимости структурного анализа существующего парка техники по статистическим данным и результатам анкетного исследования. С целью группировки особенностей технической оснащенности региона предложено использование SWOT анализа. Для повышения доступности малых форм хозяйствования к современной технике и технологиям предложено создание машинно-технологической станции в форме потребительского кооператива.
\end{abstract}

\section{KEY WORDS}

Economics; Agriculture; Technical resources; Modernization; Cooperation; Strategic analysis.

\section{КЛЮЧЕВЫЕ СЛОВА}

Экономика; Сельское хозяйство; Технические ресурсы; Модернизация; Кооперация; Стратегический анализ.

Развитие агробизнеса региона в современных условиях возможно лишь при использовании надежной, высокопроизводительной сельскохозяйственной техники. В Орловской области наблюдаются те же тенденции, что и в целом в России. Наблюдается существенное снижение количества основных видов сельскохозяйственной техники. Так, например, количество сельскохозяйственной техники в сельскохозяйственных организациях Орловской области за период 20082013 годы сократилось. Однако укажем, что в этот период существенно сократились темпы снижения технического потенциала сельского хозяйства региона и произошло обновление парка техники.[7] 
Цель исследования предложить методические подходы к обоснованию стратегических направлений технической модернизации.

\section{МАТЕРИАЛ И МЕТОДЫ ИССЛЕДОВАНИЯ}

Объектом исследования является техническая база сельскохозяйственных производителей Орловской области. Предметом исследования являются закономерности и тенденции механизма технической модернизации сельского хозяйства региона. Решению проблем фоормирования эффективного механизма модернизации сельского хозяйства и развития рынка сельскохозяйственной техники посвящены труды:, В.П. Алферьева [1], В.Т. Водянникова [2], Е.Ф. Злобина [3], И.С. Санду, В.Г. [10]., И.Г. Ушачева [11].

\section{РЕЗУЛЬТАТЫ ИССЛЕДОВАНИЯ}

При формулировании стратегических направлений технической модернизации сельского хозяйства в целом необходимо учитывать оснащенность сельскохозяйственных производителей (в том числе малых форм хозяйствования на селе (КФХ и ЛПХ)), с учетом возрастной и марочной структуры (таблица 1). Существенную долю парка техники в Орловской области составляют импортные трактора, комбайны и посевные комплексы. Причем можно указать на то, что основную часть импортных образцов техники составляет новая техника. Более половины тракторов, используемых сельскохозяйственными производителями Орловской области, произведены на заводе МТЗ. Почти половина используемых зерноуборочных комбайнов типа Дон или Акрос, причем из них менее 10\% из возрастом до 3-х лет [5]. В тоже время половина импортных зерноуборочных комбайнов новые.

Таблица 1 - Структура парка сельскохозяйственной техники в Орловской области (включая КФХ и ЛПХ) на начало 2013 года

\begin{tabular}{|c|c|c|c|}
\hline \multirow{2}{*}{ Наименование техники } & \multicolumn{2}{|r|}{ Bcero } & \multirow{2}{*}{ До 3- x лет } \\
\hline & ШТ. & Удельный вес, \% & \\
\hline Тракторы, всего, шт. & 5712 & 100,0 & 860 \\
\hline В т.ч. ПТЗ (типа К-700) всех моделей & 392 & 6,9 & 16 \\
\hline ХТ3 (типа Т-150, Т-150К) всех моделей & 1052 & 18,4 & 96 \\
\hline МТЗ всех моделей & 3012 & 52,7 & 483 \\
\hline Прочие тракторы & 805 & 14,1 & 18 \\
\hline Импортные тракторы & 451 & 7,9 & 247 \\
\hline Зерноуборочные комбайны всего, шт. & 2119 & 100,0 & 431 \\
\hline В т. . типа Дон, Акрос & 998 & 47,1 & 90 \\
\hline типа СК-5 «Нива», Вектор & 354 & 16,7 & 17 \\
\hline типа «Полесье» & 164 & 7,7 & 137 \\
\hline Типа «Енисей» & 238 & 11,2 & 12 \\
\hline Импортные & 365 & 17,2 & 175 \\
\hline Кормоуборочные комбайны, прицепные и самоходные всего, шт. & 167 & 100,0 & 30 \\
\hline В т.ч. импортные & 40 & 24,0 & 8 \\
\hline Свеклоуборочные комбайны и комплексы, шт. & 85 & 100,0 & 14 \\
\hline В т.4. импортные & 49 & 57,6 & 14 \\
\hline Сеялки, всего, шт. & 1992 & 100,0 & 195 \\
\hline В т.ч. зерновые & 1674 & 84,0 & 115 \\
\hline В т.ч. точного высева & 292 & 14,7 & 77 \\
\hline Посевные комплексы, шт. & 141 & 100,0 & 64 \\
\hline В т.ч. импортные & 138 & 97,9 & 64 \\
\hline
\end{tabular}

По результатам анкетирования сельскохозяйственных производителей Орловской области по вопросам состояния, использования и воспроизводства технической базы были выявлены следующие основные проблемы и резервы роста эфффективности: 
- более четверти организаций исследуемой совокупности имеют потребности в высококлассных механизаторах и 14\% производителей молока испытывают нехватку операторов машинного доения, то есть существует нехватка производственного персонала;

- важным вопросом эфффективного использования техники является обеспечение условий хранения, однако значительная часть техники и в летний и в зимний период хранится под открытым небо, что негативно сказывается на её готовности к полевым работам;

- фрормируя источники фринансирования воспроизводства технической базы сельскохозяйственные организации рассчитывают на собственные средства, в тоже время, используя заёмные средства предприятия стараются использовать возможности государственной поддержки;

- менее четверти производителей Орловской области молока применяют беспривязную систему содержания животных, которая позволяет получать высокий чистый доход. Причем данная система содержания животных является для России новой и её использование свидетельствует высокой технической оснащенности производства инновационным оборудованием;

- в Орловской области достаточно распространено использование систем сберегающего земледелия, что связано с их высокой экономической эфффективностью, однако все еще необходимо техническое перевооружение и модернизация навесного оборудования;

- аграрные предприятия привлекают со стороны уборочную технику, что при современном уровне цен на оказание услуг по уборке в первую очередь свидетельствует о недостаточной обеспеченности уборочной техникой, а не экономической целесообразностью.[6]

Для разработки стратегии технической модернизации сельского хозяйства определены основные проблемы стоящие перед субъектами агробизнеса региона, сфрормулированы сильные и слабые стороны участников рыночных отношений в АПК.

Таблица 2 - Стратегический (SWOT) анализ развития технической базы сельскохозяйственного производства Орловской области

1. Реализация областной целевой программы «Развитие сельского хозяйства и регулирование рынков сельскохозяйственной продукции, сырья и продовольствия на 2013-2020 годы».

2. Улучшение качества и конкурентоспособности продукции в связи с модернизацией и техническим перевооружением производства.

3. Применение инновационных технологий в сельскохозяйственных отраслях, особенно при производстве зерна, молока, мяса свиней.

4. Наличие сельскохозяйственных организаций эфрективно производящих конкурентоспособную продукцию.

\section{Возможности (O)}

1. Увеличение объемов производства и реализации сельскохозяйственной продукции.

2. Освоение ресурсо и энергосберегающих технологий.

3. Развитие малых форм хозяйствования как значимых производителей товарной сельскохозяйственной продукции

4. Повышение инвестиционной привлекательности сельского хозяйства в силу роста эффективности агробизнеса.

Слабые стороны (W)

1. Высокая доля убыточных сельхозорганизаций.

2. Неразвитость инфраструктуры рынка услуг выполнения технологических операций.

3. Низкая техническая оснащенность КФХ и лПХ.

\section{Угрозы (T)}

1. Снижение уровня прямой государственной поддержки в связи со вступлением России в ВTO.

2. Дальнейшее усиление диспаритета цен на сельскохозяйственную продукцию может привести к банкротству многих предприятий.

3. Зависимость сельскохозяйственного производства от природных фракторов.

Представленный экономический анализ технической оснащенности и эффрективности использования сельскохозяйственной техники в Орловской области показали ряд вопросов которые необходимо решить для формирования современного 
и конкурентоспособного парка техники и роста эффеективности реализации его потенциала:

1. Формирование уровня энергообеспеченности сельскохозяйственного производства на уровне свыше 200 л.с. в расчете на 100 на посевных площадей, чего можно достичь посредством формирования парка энергонасыщенной техники. То есть с учетом того, что выбывает в связи с износом зачастую техника с низкими мощностными показателями, заменяться она должна более производительной техникой.

2. Освоение нулевой и минимальной технологий требует оснащение сельскохозяйственных производителей посевными комплексами, что позволит существенно снизить ресурсо и энергоёмкость производства, однако парк тракторов должен быть сформирован из мощной техники. [4]

3. Техническое оснащение животноводства должно строиться с двух сторон: организация эффрективного кормопроизводства (обновления парка кормозаготовительной техники), создание условий по содержанию и кормлению животных (обновление доильных установок, строительство новых молочных фрерм с беспривязным содержанием животных).

4. Создание условий для интенсивного развития КФХ и ЛПХ, с доступом до эффрективных технологий производства и техники.

5. Обеспечение условий по техническому обслуживанию, ремонту и хранению сельскохозяйственной техники.

Для формирования машинно-технологической станции для обслуживания субъектом малого агробизнеса в Орловской области нами предлагается сформировать парк техники представленный в таблице 3.

Таблица 3 - Расчет капитальных затрат на фрормирование парка техники для МТС

\begin{tabular}{|c|c|c|c|c|c|c|}
\hline \multirow[b]{2}{*}{ Направления затрат } & \multicolumn{2}{|c|}{$2014-2016$ годы } & \multicolumn{2}{|c|}{$2017-2018$ годы } & \multicolumn{2}{|c|}{2019 - 2020 годы } \\
\hline & $\begin{array}{l}\text { Кол- } \\
\text { во, } \\
\text { ед. }\end{array}$ & $\begin{array}{c}\text { Сумма, } \\
\text { тыс. руб. }\end{array}$ & $\begin{array}{l}\text { Кол- } \\
\text { во, } \\
\text { ед. }\end{array}$ & $\begin{array}{l}\text { Сумма, } \\
\text { тыс. руб. }\end{array}$ & $\begin{array}{c}\text { Кол- } \\
\text { во, } \\
\text { ед. }\end{array}$ & $\begin{array}{l}\text { Сумма, } \\
\text { тыс. руб. }\end{array}$ \\
\hline $\begin{array}{c}\text { Покупка земельных участков и } \\
\text { строительство баз для хранения и } \\
\text { ремонта техники }\end{array}$ & 2 & 15000 & 0 & 0 & 0 & 0 \\
\hline $\begin{array}{c}\text { Покупка зерноуборочных комбайнов типа } \\
\text { Акрос } 530\end{array}$ & 15 & 72400 & 20 & 96500 & 20 & 96500 \\
\hline Тракторы типа К744 & 3 & 9750 & 6 & 19500 & 6 & 19500 \\
\hline Тракторы типа МТ3 82 & 12 & 21720 & 15 & 27150 & 15 & 27150 \\
\hline $\begin{array}{c}\text { Прицепной картофелеуборочный } \\
\text { комбайн }\end{array}$ & 1 & 1600 & 1 & 1600 & 1 & 1600 \\
\hline Посевной комплекс & 3 & 2160 & 6 & 4320 & 6 & 4320 \\
\hline Плуги оборотные & 3 & 1620 & 6 & 3240 & 6 & 3240 \\
\hline Культиваторы & 3 & 2100 & 6 & 4200 & 6 & 4200 \\
\hline $\begin{array}{c}\text { Автомобили КАМАЗ с полуприцепом } \\
\text { самосвалом }\end{array}$ & 5 & 17000 & 7 & 23800 & 8 & 27200 \\
\hline Сельскохозяйственный самолет & 0 & 0 & 1 & 4800 & 1 & 4800 \\
\hline Итого & & 143350 & & 185110 & & 188510 \\
\hline
\end{tabular}

Исходя из сложившихся условий можно предложить следующий механизм создания машинно-технологических станций в Орловском регионе. Организация МТС в регионе должна строиться на основе формирования механизма кооперации малых форм хозяйствования между собой и с крупным бизнесом региона.[9] Это связано с необходимостью крупных инвестиций при формировании парка техники. Данное количество техники позволит существенно повысить экономическую эфффективность производства сельскохозяйственной продукции крестьянским (фермерским) и личным подсобным хозяйствам, а также средним сельскохозяйственных организациям Орловской области. Приобретение этой техники возможно частично за счет паевых взносов участников, частично за счет кредитных ресурсов, частично за счет лизинга.

Создание машинно-технологической станции в форме потребительного 
кооператива позволит субъектам малого агробизнеса получить доступ к эффрективной, современной технике. Для создания МТС предлагается использовать паевые взносы сельскохозяйственных производителей, средства государственной поддержки, а также инвестиционные кредиты и лизинг. Основные направления деятельности машиннотехнологической станции (потребительского кооператива) заключаются в оказании услуг по проведению весенних полевых работ, уходу за посевами, уборке урожая, хранению техники, техническому обслуживании и ремонту.

Для создания организации подобного типа необходимо соблюдение нескольких условий. Во-первых, географическая близость потенциальных участников. В таком случае повышается оперативность перемещения сельскохозяйственной техники от поля к полю. Во-вторых, экономическая независимость всех участников кооператива.

Отметим, что организационно-правовая фоорма потребительский кооператив не предусматривает цели извлечение прибыли, однако удовлетворение потребности учредителей в качественных технических работах, а также развитие организации требует установления расценок на работы с учетом покрытия фрактически понесенных затрат и инфрляции. Так, например, фрактические затраты на уборку зерновых культур комбайном Акрос 530 по данным 2012 года в Орловской области составили 1300-1400 рублей на гектар. В этой связи целесообразно установить внутреннюю расценку за уборку зерновых на уровне 1570 рублей, что на 34\% ниже коммерческой стоимости оказания услуг по уборке зерновых, которая в 2012 году составила 2100 рублей. При таких условиях расчетов техника окупиться, с учетом выплат лизинговых платежей и процентов за кредит в течение 6-7 лет.

Таблица 4 - Целевые индикаторы стратегии технической модернизации сельского хозяйства Орловской области

\begin{tabular}{|c|c|c|c|c|c|c|c|c|c|c|}
\hline \multirow{2}{*}{$\begin{array}{l}\text { № } \\
\text { п.п. }\end{array}$} & \multirow{2}{*}{$\begin{array}{l}\text { Наименование целевого } \\
\text { индикатора и показателя }\end{array}$} & \multicolumn{9}{|c|}{ Годы } \\
\hline & & 2013 & 2014 & 2015 & 2016 & 2017 & 2018 & 2019 & 2020 & $\begin{array}{r}2013 \\
2020\end{array}$ \\
\hline \multirow{4}{*}{1.} & \multicolumn{10}{|c|}{ Приобретение, ед.: } \\
\hline & тракторов & 440 & 445 & 445 & 450 & 450 & 455 & 460 & 460 & 3605 \\
\hline & зерноуборочных комбайнов & $170^{\circ}$ & 170 & 175 & 175 & 175 & 175 & 180 & 180 & 1400 \\
\hline & кормоуборочных комбайнов & 10 & 10 & 12 & 12 & 14 & 14 & 15 & 15 & 102 \\
\hline \multirow{5}{*}{2.} & \multicolumn{10}{|c|}{ Коэфффиициент обновления, \%: } \\
\hline & тракторов & 7,7 & 7,8 & 7,8 & 7,9 & 7,9 & 8,0 & 8,1 & 8,1 & \\
\hline & зерноуборочных комбайнов & 8,0 & 8,0 & 8,3 & 8,3 & 8,3 & 8,3 & 8,5 & 8,5 & \\
\hline & кормоуборочных комбайнов & 6,0 & 6,0 & 7,2 & 7,2 & 8,4 & 8,4 & 9,0 & 9,0 & \\
\hline & доильных установок & 5,0 & 5,0 & 5,0 & 5,0 & 5,0 & 5,0 & 5,0 & 5,0 & \\
\hline \multirow{4}{*}{3.} & \multicolumn{10}{|c|}{ Доля техники в пределах амортизационного срока, \% } \\
\hline & тракторов & 42 & 46 & 49 & 52 & 55 & 57 & 60 & 63 & \\
\hline & зерноуборочных комбайнов & 53 & 55 & 57 & 59 & 61 & 62 & 64 & 66 & \\
\hline & кормоуборочных комбайнов & 60 & 60 & 60 & 61 & 61 & 61 & 61 & 61 & \\
\hline
\end{tabular}

На наш взгляд, индикаторы заложенные в Долгосрочной областной целевой программе «Развитие сельского хозяйства и регулирование рынков сельскохозяйственной продукции, сырья и продовольствия в Орловской области на 2013 - 2020 годы» являются вариантом пессимистического прогноза формирования парка техники отечественными образцами, а не целевыми показателями. При таком уровне обновления парка российской техникой можно говорить о деградации российского сельскохозяйственного машиностроения и о нецелевом подходе при формировании программных региональных документов. На наш взгляд минимальный годовой объем приобретения новых тракторов сельскохозяйственными организациями Орловской области должен составлять 250-300 единиц, а с учетом малых форм хозяйствования на селе 400-460 единиц. Если говорить об уборочной технике констатировать модернизацию парка в организациях можно при уровне обновления на уровне 100-130 единиц в год, а с учетом КФХ и ЛПХ 160-200 единиц. Проблемным аспектом в технической оснащенности сельского хозяйства Орловской области является техническая модернизация животноводства. В этой связи приоритетным 
направлением развития должно стать переоснащение кормопроизводства, а также содержания и кормления животных.

Нами предлагаются следующие целевые индикаторы стратегии технической модернизации сельского хозяйства Орловской области с учетом малых форм хозяйствования на селе, представленные в таблице 4.

В целом, подводя итог, следует отметить, что техническая модернизация сельского хозяйства, являясь многогранным вопросом, и требующим значительных фринансовых вложений нуждается в детальной научной проработке и обосновании.

Предложенные направления развития должны применяться с учетом региональных особенностей и современного развития технологии и техники.

\section{БИБЛИОГРАФИЯ}

[1] Алферьев В.П. Совершенствование механизма рынка средств производства для сельского хозяйств в условиях членства России в ВТО/ В.П. Алферьев, С.А. Шанин, А.В. Федотов, Г.С. Павлов, О.И.Жукова, К.И. Алексеев, С.Е. Жуковина. М.: 2013. -75 c.

[2] Водянников В.Т. Приоритеты в техническом оснащении земледелия / В.Т. Водянников, В.И. Горбачев // Достижения науки и техники АПК. - 2009. - №8.c.69-71.

[3] Злобин Е.Ф. Особенности рынка сельскохозяйственной техники Орловской области/Е.Ф. Злобин, А.А. Полухин // Экономические и гуманитарные науки.2010. -№5 c.78-84.

[4] Полухин А.А. Конкурентные преимущества производителей сельскохозяйственной техники на рынке Орловской области / А.А. Полухин // Современная конкуренция. - 2010. - №3(21). - с. 97-109.

[5] Полухин А.А. Использование материально-технических ресурсов в сельхозпредприятиях Орловской области / А.А. Полухин // АПК: экономика, управление. - 2010. - №11. - с. 122-124.

[6] Полухин А.А. Оценка состояния, использования и воспроизводства материально-технической базы сельскохозяйственных организаций Орловской области / А.А. Полухин, А.В. Алпатов, А.Н. Ставцев // Вестник ОрелГАУ. - 2012. №5 (38) c. 78-85.

[7] Полухин А.А. Организационно-экономический механизм воспроизводства технического потенциала сельского хозяйства РФ в условиях ВТО / А.А. Полухин // Образование, наука и производство. - 2012. - №1 с.22-29.

[8] Прока Н.И. Эффрективность использования ресурсного потенциала сельского хозяйства Орловской области / Н.И. Прока, А.А. Полухин, И.В. Страшко// Вестник Орел ГАУ. - 2010. - №6(27) с. 2-8.

[9] Савкин В.И. Кооперация на селе: воспоминание о будущем / В.И. Савкин, А.А. Полухин, И.В. Сафронов // Аграрная Россия. - 2013. - №4 с. 26-33.

[10] Савенко В.Г. Проблемы формирования механизма инновационного обеспечения АПК / В.Г. Савенко, И.С. Санду// АПК: экономика, управление. 2013. - №1. - c. 28-33.

[11] Ушачев И.Г. Государственная программа развития сельского хозяйства и регулирования рынков сельскохозяйственной продукции, сырья $и$ продовольствия на 2013-2020 гг.: научное обеспечение / И.Г. Ушачев // Экономика сельскохозяйственных и перерабатывающих предприятий. 2013.№4. - C. 5-11. 